\title{
Endolymphatic Sac Tumor
}

National Cancer Institute

\section{Source}

National Cancer Institute. Endolymphatic Sac Tumor. NCI Thesaurus. Code C67560.

An aggressive epithelial neoplasm arising from the temporal bone. It is characterized by the presence of a papillary pattern, and has been described as an adenoma or carcinoma in the literature. 